\title{
ANALISIS NILAI TAMBAH DAN KELAYAKAN USAHA PENGGILINGAN PADI DI KECAMATAN BUAY BAHUGA, KABUPATEN WAY KANAN, LAMPUNG Oleh : Ary Eko Prastya Putra
}

\author{
Staf Pengajar Sekolah Tinggi Ilmu Pertanian Belitang \\ Jln.Kampus Pertanian No.3 Belitang Kab.OKU Timur Prov.Sumatera Selatan \\ e-mail: ary.sped88@gmail.com
}

\begin{abstract}
The objectives of this research are: 1) To know the production cost and income of paddy mill business in Buay Bahuga Sub-district of Way Kanan Regency, 2) To know the value added of rice mill business in Buay Bahuga Sub-district of Way Kanan Regency, 3) To know the feasibility of rice milling business in the District of Buay Bahuga District Way Kanan. The results showed that the total production of rice milling business that is equal to $75.096 \mathrm{~kg} /$ year with the selling price of $\mathrm{Rp} \mathrm{7,700} \mathrm{/}$ $\mathrm{kg}$, the revenue of $R p$ 578,239,200 is obtained, the use of production cost of $R p$ 800.006.105, the income of $R p-221.766 .905$. Added value to the paddy mill business in Buay Bahuga District is Rp 578,239,200. with the use of the intermediate fee of $R p$ 382,505,680. The rice milling business in Kecamatan Buay is also feasible to be developed financially.
\end{abstract}

Key Words : Rice, Value-added, Feasibility.

\section{PENDAHULUAN}

\section{A. Latar Belakang}

Beras adalah komoditas strategis dan merupakan pangan pokok bangsa Indonesia. Konsumsi beras setiap tahun selalu meningkat seiring dengan laju penambahan penduduk. Swasembada beras terjadi tahun 1984 dan dapat dipertahankan pada tahun 1990. Setelah itu peningkatan konsumsi beras tidak sebanding lagi dengan laju peningkatan produksi dan areal panen (Kartono et al., 2004).

Masalah utama dalam penanganan pasca panen padi yang sering dialami oleh petani adalah tingginya kehilangan hasil selama pasca panen. BPS (2008) menyebutkan kehilangan hasil panen dan pascapanen akibat dari ketidak sempurnaan penanganan pasca panen mencapai $20,51 \%$, dimana kehilangan saat pemanenan $9,52 \%$, perontokan $4,78 \%$, pengeringan $2,13 \%$ dan penggilingan $2,19 \%$.

Kecamatan Buay Bahuga Kabupaten Way Kanan terdapat usaha penggilingan padi skala kecil yaitu mengolah padi menjadi beras siap konsumsi yang beroperasi setiap musim panen padi berkisar antara Bulan Maret dan Bulan September, sehingga produksi beras yang dihasilkan dapat memenuhi kebutuhan konsumsi beras pada tingkat kecamatan, tingkat kabupaten dan tingkat

\section{B. Rumusan Masalah}

Rumusan dalam penelitian ini adalah sebagai berikut :

1. Berapa besar biaya produksi dan pendapatan pada usaha penggilingan padi di Kecamatan Buay Bahuga Kabupaten Way Kanan?

2. Berapa nilai tambah usaha penggilingan padi di Kecamatan Buay Bahuga Kabupaten Way Kanan ?

3. Apakah usaha penggilingan padi di Kecamatan Buay Bahuga Kabupaten Way Kanan layak untuk dikembangkan?

\section{Tujuan dan Kegunaan}

Tujuan dari penelitian ini adalah :

1. Untuk Mengetahui biaya produksi dan pendapatan pada usaha penggilingan padi di Kecamatan Buay Bahuga Kabupaten Way Kanan.

2. Untuk Mengetahui nilai tambah usaha penggilingan padi di Kecamatan Buay Bahuga Kabupaten Way Kanan.

3. Untuk Mengetahui kelayakan usaha penggilingan padi di Kecamatan Buay Bahuga Kabupaten Way Kanan. 
Kegunaan dari penelitian ini adalah :

1. Memberikan gambaran kepada mahasiswa tentang biaya produksi dan pendapatan pada penggilingan padi.

2. Mampu memberikan wawasan pengetahuan bagi lembaga dan sebagai bahan referensi bagi peneliti selanjutnya.

\section{KERANGKA TEORITIS}

\section{A. Tinjauan Pustaka}

\section{B. Model Pendekatan}

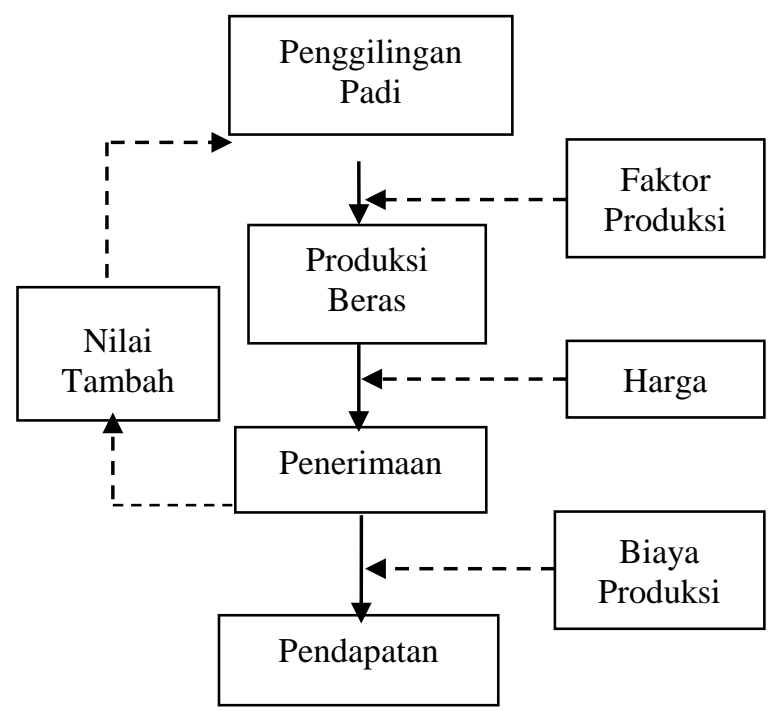

Keterangan :

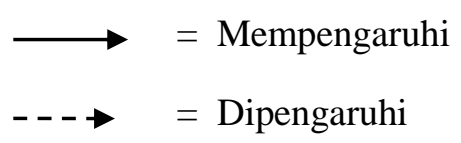

Gambar 1. Model Pendekatan Diagramatis Usaha Penggilingan Padi.

Data yang diperoleh di lapangan dikelompokkan secara tabulasi lalu dianalisis secara matematis.

$$
\mathrm{TC}=\mathrm{FC}+\mathrm{VC}
$$

Keterangan :

$\mathrm{TC}=$ Total Cost $(\mathrm{Rp} /$ Proses Produksi $)$

$\mathrm{FC}=$ Fixed Cost (Rp/Proses Produksi)

$\mathrm{VC}=$ variabel cost $(\mathrm{Rp} /$ Proses Produksi $)$

$$
\mathrm{R}=\mathrm{P} \times \mathrm{Y}
$$

Keterangan :

$\mathrm{R}=$ Revenue $(\mathrm{Rp} /$ Proses Produksi)

$\mathrm{Y}=$ Yield $(\mathrm{Rp} /$ Proses Produksi)

$\mathrm{P}=$ Price $(\mathrm{Rp} /$ Proses Produksi)

$$
\mathrm{I}=\mathrm{TR}-\mathrm{TC}
$$

Keterangan :

$\mathrm{I}=$ Income $(\mathrm{Rp} /$ Proses Produksi)

$\mathrm{TR}=$ Total Revenue $(\mathrm{Rp} /$ Proses Produksi $)$

$\mathrm{TC}=$ Total Cost $(\mathrm{Rp} /$ Proses Produksi $)$

$$
\mathrm{NT}=\mathrm{TR}-\mathrm{IC}
$$

Dimana :

NT = Nilai Tambah

$\mathrm{TR}=$ Total Revenue $(\mathrm{Rp} /$ Proses $)$

$\mathrm{IC}=$ Intermidiet Cost

Untuk menghitung kelayakan finansial sebagai berikut ;

a. Net Present Value (NPV)

Dimana :

$$
N P V=\sum_{t=1}^{n} \frac{(B-C-i)}{t-1}
$$

$\mathrm{B}=$ Benefit (Pendapatan Bersih)

$\mathrm{C}=\operatorname{Cost}$ (Total Biaya)

$\mathrm{I}=$ Investasi

b. IRR (Internal Rate of Return)

c.

$$
I R R=i 1+\frac{N P V}{N P V 1+N P V 2}(i 2-i 1)
$$

Dimana

$\mathrm{NPV}_{1}=\mathrm{NPV}$ yang positif mendekati 0

$\mathrm{NPV}_{2}=\mathrm{NPV}$ yang negatif mendekati 0

$\mathrm{i}_{1}=$ tingkat bunga rendah yang menghasilkan $\mathrm{NPV}_{1}$

$\mathrm{i}_{2}=$ tingkat bunga yang lebih tinggi menghasilkan $\mathrm{NPV}_{2}$

c. Net $\mathrm{B} / \mathrm{C}$

$$
\text { Dimana } N E T B / C=\frac{\sum_{t=1}^{n} \frac{B_{t}-C_{t}}{(1+i)^{t}}}{\sum_{t=1}^{n} \frac{C_{t}-B_{t}}{(1+i)^{t}}}
$$

$\mathrm{B}_{\mathrm{t}}=$ Manfaat (Benefit) pada tahun ke- $\mathrm{t}$

$\mathrm{C}_{\mathrm{t}}=$ Biaya $($ Cost $)$ pada tahun ke-t

$\mathrm{i}=$ Discount Factor

$\mathrm{t}=$ Umur proyek 


\section{C.Hipotesis}

berikut :

1. Bahwa biaya produksi pada usaha penggilingan padi di Kecamatan Buay Bahuga Kabupaten Way Kanan lebih kecil daripada penerimaan.

2. Bahwa usaha penggilingan padi di Kecamatan Buay Bahuga Kabupaten Way Kanan memberikan nilai tambah.

3. Bahwa usaha usaha penggilingan padi di Kecamatan Buay Bahuga Kabupaten Way Kanan layak untuk dikembangkan.

\section{Batasan-Batasan}

Adapun batasan penelitian ini adalah sebagai berikut :

1. Harga gabah perkilogram di Kecamatan Buay Bahuga adalah 3.600/kg.

2. Biaya tetap (Rp/Unit).

3. Biaya variabel (Rp/proses produksi).

4. Produksi adalah hasil produksi fisik berupa beras dalam satu kali proses produksi $(\mathrm{Kg})$.

5. Harga jual adalah harga jual rata - rata produksi beras yang berlaku di wilayah sekitar usaha penggilingan padi ( $\mathrm{Rp} / \mathrm{kg})$.

6. Penerimaan usaha adalah jumlah produksi fisik yang dihasilkan dikalikan dengan harga setiap satuan produksi $(\mathrm{Rp} / \mathrm{kg})$. .

7. Pendapatan usaha adalah selisih dari penerimaan usaha dengan biaya yang dikeluarkan dalam proses produksi ( $\mathrm{Rp} / \mathrm{kg}$ ).

\section{E. Metode Penelitian dan Penarikan Contoh}

Metode yang digunakan dalam penelitian ini adalah sensus akan mengambil sampel populasi pada usaha penggilingan padi pada penelitian ini, yaitu terdapat 5 usaha penggilingan padi di Kecamatan Buay Bahuga yang terdapat di Desa Trimoharjo dan Desa Sumber Jaya, di Desa Trimoharjo terdapat 3 penggilingan padi dan di Desa Sumber Jaya terdapat 2 usaha.

\section{HASIL DAN PEMBAHASAN}

\section{A. Keadaan Umum}

\section{B. Analisis Usaha Penggilingan Padi}

Hasil penelitian pada usaha penggilingan padi di Kecamatan Buay Bahuga dihitung selama 3 tahun dari jalannya usaha penggilingan padi dari tahun 2015 sampai dengan tahun 2017.

Tabel 2. Biaya Tetap pada Usaha Penggilingan Padi Di Kecamatan Buay Bahuga

\begin{tabular}{|c|c|c|c|c|c|}
\hline \multirow[t]{2}{*}{ No } & \multirow[t]{2}{*}{ Investasi } & \multicolumn{3}{|c|}{ Tahun } & \multirow[t]{2}{*}{ Jumlah } \\
\hline & & 2015 & 2016 & 2017 & \\
\hline & Pembuatan & & & & \\
\hline 1 & Bangunan & 322.000 .000 & - & - & 322.000 .000 \\
\hline 2 & Mesin & 77.400 .000 & - & - & 77.400 .000 \\
\hline 3 & Lori & 1.150 .200 & - & - & 1.150 .200 \\
\hline 4 & Skop & 240.000 & - & - & 240.000 \\
\hline 5 & Timbangan & 850.000 & - & - & 850.000 \\
\hline 6 & Bak Besar & 189.700 & - & 79.000 & 268.700 \\
\hline 7 & Ember & 33.800 & 34.800 & 34.800 & 103.400 \\
\hline 8 & Gayung & 11.100 & 11.100 & 11.100 & 33.300 \\
\hline 9 & Terpal & 63.625 & 66.583 & 66.583 & 196.792 \\
\hline & Jumlah & 401.938 .425 & 112.483 & 191.483 & 402.242 .392 \\
\hline
\end{tabular}

Sumber : Olahan Data Primer

Berdasarkan tabel di atas usaha penggilingan padi untuk biaya investasi penggunaan alat dan sewa tempat selama tiga tahun memerlukan biaya untuk tahun 2015 adalah sebesar Rp 401.938.425, tahun 2016 sebesar $\mathrm{Rp} 112.483$ dan pada tahun 2017 memerlukan biaya investasi sebesar $\mathrm{Rp}$ 191.483. Total biaya investasi dari tahun 2015 2017 adalah sebesar Rp 404.294.192.

Tabel 3. Penggunaan Biaya Variabel Usaha Penggilingan Padi

\begin{tabular}{rlrrrr}
\hline \multirow{2}{*}{$\begin{array}{c}\mathrm{N} \\
\mathrm{o}\end{array}$} & $\begin{array}{c}\text { Operasiona } \\
1\end{array}$ & \multicolumn{3}{c}{ Tahun } & \multirow{2}{*}{ Jumlah } \\
\cline { 3 - 5 } & & 2015 & 2016 & \multicolumn{1}{c}{2017} & \\
\hline & Pembelian & 377.600 .00 & 649.080 .00 & 540.000 .00 & 1.566 .680 .00 \\
1 & Gabah & 0 & 0 & 0 & 0 \\
& & & & & \\
2 & Karung & 3.137 .200 & 5.395 .800 & 4.416 .000 & 12.949 .000 \\
& & & & & \\
3 & Solar & 802.480 & 1.369 .200 & 1.103 .200 & 3.274 .880 \\
& Jarum & & & & \\
4 & Karung & 98.000 & 168.000 & 116.000 & 382.000 \\
& & & & & \\
5 & Telepon & 168.000 & 288.000 & 240.000 & 696.000
\end{tabular}




\begin{tabular}{rlrrrr}
6 & $\begin{array}{l}\text { Sarana } \\
\text { Pabrik }\end{array}$ & 700.000 & 1.656 .000 & 1.680 .000 & 4.036 .000 \\
& $\begin{array}{l}\text { Tenaga } \\
7\end{array}$ & & & & \\
Kerja & 15.562 .000 & 28.815 .600 & 21.248 .000 & 65.625 .600 \\
\hline & Jumlah & $\begin{array}{rrrr}\text { 398.067.68 } \\
\text { Biaya }\end{array}$ & $\begin{array}{r}686.772 .60 \\
0\end{array}$ & $\begin{array}{r}568.803 .20 \\
0\end{array}$ & $\begin{array}{r}1.653 .643 .48 \\
0\end{array}$ \\
\hline
\end{tabular}

Sumber : Olahan Data Primer

Tabel 4. Biaya Tetap dan Biaya Variabel

\begin{tabular}{|c|c|c|c|c|c|}
\hline \multirow{2}{*}{ No } & \multirow{2}{*}{ Uraian } & \multicolumn{4}{|c|}{ Tahun } \\
\hline & & 2015 & 2016 & 2017 & Jumlah \\
\hline 1 & $\begin{array}{l}\text { Biaya } \\
\text { Tetap }\end{array}$ & 401.938 .425 & 112.483 & 191.483 & 404.294 .192 \\
\hline 2 & $\begin{array}{l}\text { Biaya } \\
\text { Variabel }\end{array}$ & 398.067 .680 & 686.772 .600 & 568.803 .200 & 1.653.643.480 \\
\hline \multicolumn{2}{|c|}{ Total Biaya } & 800.006 .105 & 686.885 .083 & 568.994 .683 & 2.057 .937 .672 \\
\hline
\end{tabular}

Sumber : Olahan Data Primer,

Total biaya produksi usaha penggilingan padi dari tahun 2015 sampai dengan tahun 2017 yang terdiri dari biaya tetap dan biaya variabel yaitu pada tahun 2015 penggunaan biaya produksi sebesar Rp 800.006.105/tahun, tahun 2016 sebesar Rp 686.885.083/tahun, dan tahun 2016 adalah sebesar Rp 568.994.683/tahun dengan penggunaan biaya produksi sebesar Rp 2.057.937.672.

Produksi merupakan hasil usaha yang dikalikan dengan harga jual, penerimaan merupakan hasil kotor sebelum dikurangi pengguaan biaya produksi. Pendapatan adalah penerimaan yang diperoleh petani dari pengelolaan suatu kegiatan usaha, setelah dikurangi dengan seluruh biaya yang dikeluarkan.

Tabel 5. Penerimaan dan Pendapatan pada Usaha Penggilingan Padi

\begin{tabular}{|c|c|c|c|c|}
\hline \multirow{2}{*}{$\begin{array}{l}\mathrm{N} \\
\mathrm{O}\end{array}$} & \multirow{2}{*}{ Uraian } & \multicolumn{3}{|c|}{ Tahun } \\
\hline & & 2015 & 2016 & 2017 \\
\hline 1 & Beras & 75.096 & 127.008 & 105.840 \\
\hline 2 & Harga & 7.700 & 7.700 & 7.700 \\
\hline 3 & $\begin{array}{l}\text { Penerima } \\
\text { an }\end{array}$ & $\begin{array}{r}578.239 .2 \\
00\end{array}$ & $\begin{array}{r}977.961 .6 \\
00\end{array}$ & $\begin{array}{r}814.968 .0 \\
00\end{array}$ \\
\hline 4 & $\begin{array}{l}\text { Biaya } \\
\text { Produksi }\end{array}$ & $\begin{array}{r}800.006 .1 \\
05\end{array}$ & $\begin{array}{r}686.772 .6 \\
00\end{array}$ & $\begin{array}{r}568.803 .2 \\
00\end{array}$ \\
\hline 5 & $\begin{array}{l}\text { Pendapat } \\
\text { an }\end{array}$ & $\begin{array}{r}221.766 .9 \\
05\end{array}$ & $\begin{array}{r}291.189 .0 \\
00\end{array}$ & $\begin{array}{r}246.164 .8 \\
00\end{array}$ \\
\hline
\end{tabular}

Sumber : Olahan Data Primer

Pada tabel di atas jumlah produksi usaha penggilingan padi pada tahun 2015 belum dapat memberikan keuntungan usaha karena biaya investasi lebih besar dari pendapatan produksi yaitu sebesar $75.096 \mathrm{~kg} /$ tahun dengan harga jual Rp 7.700/kg maka diperoleh penerimaan usaha sebesar Rp 578.239.200, penggunaan biaya produksi sebesar Rp 800.006.105, maka diperoleh pendapatan sebesar Rp - 221.766.905.

Tahun 2016 usaha penggilingan padi atau tahun ke 2 jumlah produksi adalah sebesar $127.008 \mathrm{~kg} /$ tahun dengan harga jual $\mathrm{Rp}$ $7.700 / \mathrm{kg}$, dengan penerimaan adalah sebesar Rp 977.961.600, penggunaan biaya produksi sebesar Rp 686.772.600, dan pendapatan diperoleh sebesar Rp 291.189.000.

Tahun 2017 usaha penggilingan padi adalah sebesar $105.840 \mathrm{~kg} /$ tahun harga jual $\mathrm{Rp}$ $7.700 / \mathrm{kg}$ maka penerimaan produksi adalah sebesar Rp 814.968.000, biaya produksi pada tahun 2017 adalah sebesar Rp 568.803.200/tahun dengan pendapatan diperoleh Rp 246.164.800.

Tabel 6. Nilai Tambah Usaha Penggilingan Padi

\begin{tabular}{|c|c|c|c|c|}
\hline $\begin{array}{l}\mathrm{N} \\
\mathrm{O}\end{array}$ & $\begin{array}{c}\text { Tahu } \\
\mathrm{n}\end{array}$ & $\begin{array}{l}\text { Penerimaan } \\
\text { (Rp/Tahun) }\end{array}$ & $\begin{array}{c}\text { Biaya } \\
\text { Antara } \\
(\mathrm{Rp} / \mathrm{Tahu} \\
\mathrm{n})\end{array}$ & $\begin{array}{c}\text { Nilai } \\
\text { Tambah } \\
\text { (Rp/Tahu } \\
\mathrm{n})\end{array}$ \\
\hline & & 578.239 .20 & 382.505 .6 & 188.279 .3 \\
\hline 1 & 2015 & 0 & 80 & 60 \\
\hline & & 977.961 .60 & 657.957 .0 & 296.077 .2 \\
\hline 2 & 2016 & 0 & 00 & 00 \\
\hline & & 814.968 .00 & 547.555 .2 & 256.768 .3 \\
\hline 3 & 2017 & 0 & 00 & 20 \\
\hline
\end{tabular}

Sumber : Olahan Data Primer

Berdasarkan tabel diatas penerimaan usaha penggilingan padi pada tahun $2015 \mathrm{Rp}$ 578.239.200. dengan penggunaan biaya antara sebesar Rp 382.505.680, maka nilai tambah usaha penggilingan padi pada tahun 2016 adalah sebesar Rp 188.279.360. Tahun 2015 penerimaan sebesar $\mathrm{Rp} 977.961 .600$ dengan biaya antara Rp. 657.957.000 maka nilai tambah diperoleh Rp 296.077.200. Tahun 2017 penerimaan sebesar $\mathrm{Rp}$ 814.968.000 dengan penggunaan biaya antara Rp 547.555.200 maka niali tambah pada usaha pembuatan tepung beras pada tahun 2017 adalah sebesar Rp 256.768.320.

Tingkat kelayakan pada usaha penggilingan padi di Kecamatan Buay Bahuga, berdasarkan olahan data primer tingkat kelayakan usaha sebagaimana pada tabel berikut 
Tabel 7. Nilai Rata-rata Tingkat Kelayakan (NPV) Agribisnis Usaha Penggilingan Padi Selama 3 Tahun.

\begin{tabular}{|c|c|c|c|c|c|c|c|}
\hline Talin Ke Talin & 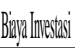 & 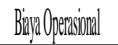 & Totalcost & Pextriman & Perlogitan & $\mathrm{CF} 188 \mathrm{C}$ & IrextVadel18\% \\
\hline $22,1,15$ & 410,984,45 & $390,06,600$ & $800,060,115$ & 588,3992010 & $.211,769,950$ & 1.99 & $.387,782,239$ \\
\hline 12,116 & 112498 & 066,7272600 & $686,77,6,600$ & $977,96,1,600$ & $291,19,0,00$ & 1.18 & $34,6(1), 000$ \\
\hline 02,017 & $19,4,40$ & $5680,002,200$ & $568 \times 1030200$ & $81,968,00$ & $246,16,5,500$ & 1.0 & $240,16,000$ \\
\hline & 402424.392 & 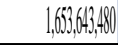 & 2065558191965 & $2371,168,900$ & $315560,8,94$ & |Miai IPY IPI & 200999,5801 \\
\hline
\end{tabular}

Olahan Data Primer

Berdasarkan uraian diatas diperoleh pada analisis nilai terkini net present value pada usaha agribisnis penggilingan padi diperoleh keuntungan sebesar Rp 280.979.581. artinya pada tingkat pendapatan yang telah dikenakan biaya bunga $18 \%$ masih memperoleh pendapatan usaha karena nilai NPV $18 \%$ adalah positif, sehingga usaha penggilingan padi di Kecamatan Buay Bahuga layak untuk dikembangkan secara finansial. Selanjutnya diperoleh nilai IRR pada usaha agribisnis penggilingan padi adalah sebagai berikut

$$
\begin{aligned}
& \left.\mathrm{IRR}=\quad \begin{array}{ccc}
\mathrm{i} 1 & \mathrm{NPV}+ \\
+ & (\mathrm{NPV+})- & \mathrm{NPV}-{ }^{\prime}
\end{array} \quad \text { (i2 - i1 }\right) \\
& \begin{array}{rlccc}
\text { IRR } & = & 18 & 280.979 .581 & \\
& + & 282.023 .912 & \\
& 18 & & \\
& + & \frac{280.979 .581}{282.023 .912} &
\end{array} \\
& =\begin{array}{ccc}
18 & & \\
+ & 0,996 & \mathrm{x}
\end{array} \\
& =\quad+\quad 10,959 \\
& =28,96
\end{aligned}
$$

Nilai ini lebih besar dari 18\% yang artinya usaha agribisnis penggilingan padi mendapatkan keuntungan dibandingkan jika jumlah dana investasi hanya disimpan di bank. Karena nilai $28,96 \%$, lebih besar dari suku bunga bank yang berlaku (18\%), maka usaha agribisnis penggilingan padi layak dikembangkan secara finansial dan usaha dapat diteruskan.
Tabel 8. Analisis Net B/C Penggilingan Padi

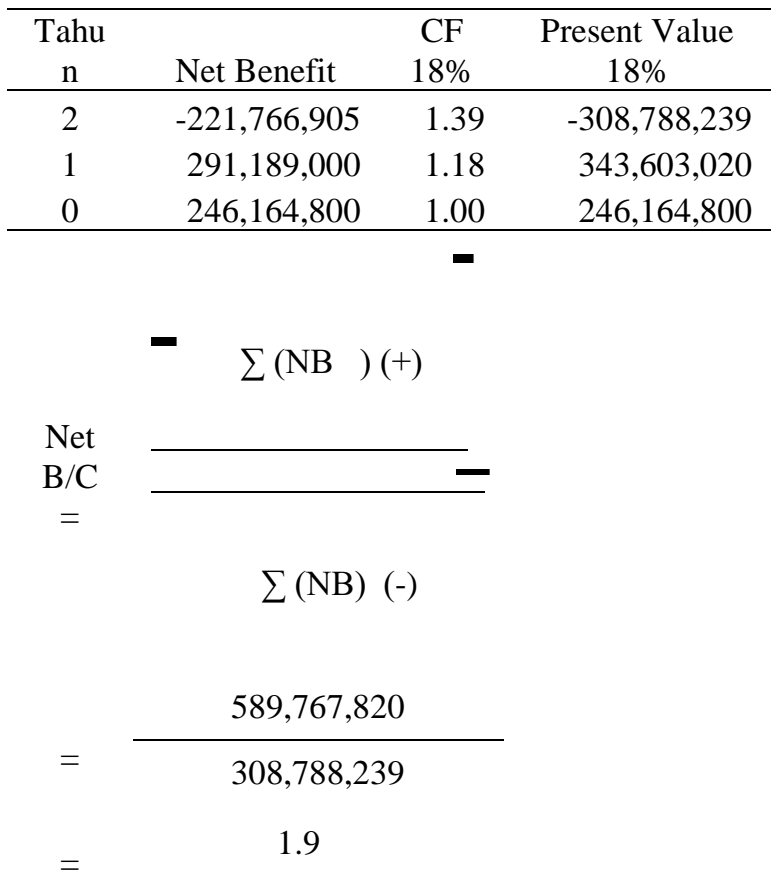

Suatu proyek layak dan efisien untuk dilaksanakan jika nilai Net $\mathrm{B} / \mathrm{C}>1$, yang berarti manfaat yang diperoleh lebih besar dari biaya yang dikeluarkan. Sebaliknya jika Net $\mathrm{B} / \mathrm{C}<0$, berarti manfaat yang diperoleh tidak cukup untuk menutupi biaya yang dikeluarkan sehingga proyek tidak layak dan efisien untuk dilaksanakan. Pada nilai Net B/C diperoleh 1,9 yang artinya modal usaha yang digunakan akan memperoleh keuntungan setelah dikenakan bunga bank sebesar Rp 1,9.- dari penggunaan modal usaha. Dengan demikian bahwa usaha agribisnis penggilingan padi layak untuk dikembangkan.

\section{KESIMPULAN DAN SARAN}

\section{A. Kesimpulan}

Kesimpulan berdasarkan hasil analisis data dan pembahasan pada usaha penggilingan padi di Kecamatan Buay Bahuga adalah sebagai berikut:

1. Jumlah produksi usaha penggilingan padi yaitu sebesar $75.096 \mathrm{~kg} /$ tahun dengan harga jual Rp 7.700/kg maka diperoleh penerimaan usaha sebesar Rp 578.239.200, penggunaan biaya produksi sebesar $\mathrm{Rp}$ 800.006.105, maka diperoleh pendapatan sebesar Rp -221.766.905.

2. Nilai tambah pada usaha penggilingan padi di Kecamatan Buay Bahuga Rp 
ISSN : 2598-0521

578.239.200. dengan penggunaan biaya antara sebesar Rp 382.505.680,

3. Usaha penggilingan padi di Kecamatan Buay bahuga layak untuk dikembangkan secara finansial.

\section{B. Saran}

Saran penulis dari penelitian yang telah dilaksanakan pada usahapenggilingan padi di Kecamatan Buay bahuga adalah sebagai berikut

1. Untuk pelaku usaha penggilingan padi, diharapkan mampu meningkatkan omzet dengan meningkatkan penjualan. Hal ini adalah cara perbaikan usaha agar usaha dapat dinilai layak dan lebih efektif dan efisien

2. Untuk pelaku usaha penggilingan padi diharapkan untuk memberikan atau menambahkan label dan izin usaha pada usaha penggilingan padi supaya dapat diketahui oleh masyarakat luas serta menyangkut pada keamanan beras untuk dikonsumsi masyarakat.

\section{DAFTAR PUSTAKA}

Teknologi Pascapanen. Departemen Pertanian. Jakarta. Diakses 27 Maret 2016

BPS. 2013. Pedoman Teknis Sekolah Lapangan Pengolahan Tanaman Terpadu (SLPTT) Tahun2013. (http://litbang.deptan.go.id/ind/pdf), Diakses 27 Maret 2016.

Nazir, M. 2011. Metode Penelitian. Ghalia Indonesia. Bogor.

Patiwiri, A. W. 2006. Teknologi Penggilingan Padi. Gramedia Pustaka Utama, Jakarta.

Suratiyah, K. 2006. Ilmu Usaha Tani. Penebar Swadaya : Jakarta

Walgito. (2010). Bimbingan dan Konseling Studi \& Karir. Yogjakarta.

Yudi, B. 2010. Sistem Agribisbis Terintegrasi Hulu-Hilir. Muara Indah. Bandung.

https ://id.wikipedia.org/wiki/pengertian survei metode penelitian. Diakses 29 Maret 201 